Clemson University

TigerPrints

$11-2016$

Characterizing Teaching Assistants' Knowledge and Beliefs Following Professional Development Activities within an InquiryBased General Chemistry Context

Lindsay B. Wheeler

Jennifer L. Maeng

Brooke A. Whitworth

Follow this and additional works at: https://tigerprints.clemson.edu/teach_learn_pub

Part of the Science and Mathematics Education Commons 


\title{
Characterizing Teaching Assistants' Knowledge and Beliefs Following Professional Development Activities within an Inquiry- Based General Chemistry Context
}

\author{
Lindsay B. Wheeler* \\ Department of Chemistry, University of Virginia, Charlottesville, Virginia 22904, United States
}

Jennifer L. Maeng

Curry School of Education, University of Virginia, Charlottesville, Virginia 22904, United States

\author{
Brooke A. Whitworth \\ Center for Science Teaching \& Learning, Northern Arizona University, Flagstaff, Arizona 86011, United States
}

\section{Supporting Information}

\begin{abstract}
The purpose of this investigation was to explore changes in undergraduate and graduate teaching assistants (TAs') content knowledge and beliefs about teaching within the context of an inquiry-based laboratory course. TAs received professional development (PD), which was informed by the TA training literature base and was designed for TAs implementing a guided inquiry approach to general chemistry laboratory instruction. TAs engaged in $\sim 20 \mathrm{~h}$ of presemester PD and $\sim 30 \mathrm{~h}$ of weekly follow-up PD during the semester. The study utilized a multiple-methods approach within a social constructivist framework to assess changes in the TAs. Participants included eight graduate TAs and five undergraduate TAs. Data collection included TA pre-PD, post-PD, and semester-end surveys and two interviews of a subset of participants. The quantitative data were analyzed using descriptive and nonparametric statistics, and the qualitative data were analyzed using systematic data analysis. The results indicate that TAs' content knowledge significantly improved following the $\mathrm{PD}$ ( mean $=80.22$, standard deviation $=$ 11.80) $(Z=-2.346, p=0.019)$ and was maintained over the semester. Following PD, the TAs shifted their beliefs to be more aligned with inquiry-based instruction. The results of this investigation suggest that TA previous experience and teaching students in an inquiry-based lab may influence TAs' beliefs. Future research will focus on examining the impact of TAs on student outcomes within a guided inquiry approach to general chemistry laboratory instruction.
\end{abstract}

KEYWORDS: First-Year Undergraduate/General, Chemical Education Research, Laboratory Instruction, Inquiry-Based/Discovery Learning, TA Training/Orientation

FEATURE: Chemical Education Research

\section{INTRODUCTION}

In large-enrollment laboratory courses, teaching assistants (TAs), typically graduate students, are often students' primary contacts. $^{1,2}$ As a result, they are well-situated to make an important contribution to quality undergraduate education ${ }^{3}$ and can influence retention of students majoring in the sciences. ${ }^{4,5}$ They may also impact how much students learn in the laboratory. ${ }^{6}$ With the growing number of students enrolled in colleges and universities, ${ }^{7}$ undergraduates are being more frequently utilized as TAs in laboratory contexts. ${ }^{8,9}$ Building on our previous understanding of TAs' perceptions of professional development (PD), ${ }^{10}$ the purpose of the present study was to examine changes in both undergraduate and graduate TAs' content knowledge and teaching beliefs within the context of a TA PD and an inquiry-based general chemistry laboratory.

\section{Laboratory Teaching Assistants}

Research on laboratory TAs suggests that content knowledge, teaching beliefs, and prior knowledge impact TAs' instruc- tion. ${ }^{3,11,12}$ Content knowledge is a component of pedagogical content knowledge (PCK) ${ }^{13}$ and is foundational to how teachers develop their PCK. However, indirect measures such as college degree ${ }^{14}$ and $\mathrm{PCK}^{15}$ are most frequently used as measures of content knowledge, and some researchers have argued that these are inaccurate measures of content knowledge. ${ }^{16}$ Only one study, to our knowledge, directly measured both content knowledge and PCK of graduate teaching assistants (GTAs). ${ }^{17}$ The authors developed and validated a context-specific assessment and found that TAs had a good grasp of thin-layer chromatography content. Content knowledge of TAs in other areas has not been investigated. Further, while some research alludes to the importance of knowledge expertise in undergraduate tutors, ${ }^{18}$ no studies have examined

Received: May 21, 2016

Revised: October 13, 2016 
the content knowledge of undergraduate teaching assistants (UTAs). Thus, work to understand both UTA and GTA content knowledge and how content knowledge changes as a result of $\mathrm{PD}$ and teaching, particularly in an inquiry-based context, is warranted.

Teaching beliefs, or "the epistemological commitments to how a content domain should be taught", 19 can influence teaching practice. $^{20,21}$ For example, in a case study of a physics GTA, Volkmann and Zgagcz ${ }^{12}$ found that the TA's belief that instructors should tell students correct answers was a barrier to how they interacted with students in an inquiry-based laboratory. Further, the course context may also inform TA beliefs. $^{20,21}$ Addy and Blanchard ${ }^{20}$ found that biology GTAs held transitional beliefs and taught using traditional methods, which the authors attributed to the constraints of the traditional laboratory curriculum. In another study of GTAs, Sandi-Urena and Gatlin ${ }^{21}$ found qualitative differences in TAs' self-image in traditional and inquiry-based laboratories. This self-image was informed by TAs' beliefs about laboratory teaching and the nature of knowledge. To our knowledge, no studies have examined UTAs' teaching beliefs and few have examined GTA beliefs within an inquiry-based laboratory course. ${ }^{21}$ Given the importance of beliefs on practice, more research in this area is needed.

Finally, GTAs and UTAs typically have little or no previous teaching experience, ${ }^{8,22}$ nor have they experienced inquiry-based instruction as students or teachers. Even the most experienced instructors struggle to implement instructional approaches such as inquiry because of their own experiences and beliefs. ${ }^{20,23}$ Thus, supporting TAs in inquiry-based instructional strategies and understanding how to promote deep content knowledge and beliefs aligned with inquiry-based teaching are vital to the successful implementation of such a curriculum.

\section{Professional Development for Teaching Assistants}

Many GTAs will become faculty members with instructional duties in science departments, and TA professional development (PD) may be the only formal teaching support they receive. $^{20}$ Thus, it is essential to develop PD for TAs that not only prepares them for their immediate TA position but helps promote teaching beliefs and practices that align with reformbased instruction they can use in their future teaching careers. The literature on PD and TA training suggests that PD should incorporate the following to support TAs' teaching:

- opportunities for TAs to act as students, have appropriate TA-student interactions modeled, and practice using these modeled approaches; ${ }^{22-24}$

- explicit instruction on TA expectations and opportunities for TAs to practice grading; $5,15,26$

- discussion of teaching beliefs and time for reflection on teaching; ${ }^{23,26}$

- learning about the learning process, how to teach, and why it is important to teach. ${ }^{21,25,27}$

Despite these suggested components of training, few studies have examined PD for TAs or the characteristics of TAs within an inquiry-based laboratory context. ${ }^{10,11,21,22,28}$ Further, few studies have examined UTAs in roles parallel to GTAs in the laboratory context. ${ }^{8,17}$ Therefore, researchers have called for further empirical studies on TAs and TA programs. ${ }^{24,27,29}$

\section{THEORETICAL FRAMEWORK}

The relationship between beliefs, knowledge, and teaching practice is complex. $^{30}$ The knowledge teachers choose to acquire and how they interpret this knowledge is based on their beliefs. ${ }^{30,31}$ For example, if a teacher has the belief that scientific knowledge is unchanging, that teacher may choose not to learn about the latest developments in science. This lack of content knowledge would then likely negatively impact both PCK and instruction. In the present study, TAs were provided PD that emphasizes particular content knowledge related to the course curriculum and engaged in interactions with students around this particular knowledge. Examining both TA beliefs and knowledge in the present study may inform the knowledgebeliefs relationship.

The relationship between beliefs and practice is contested between researchers. ${ }^{13,31}$ For example, Shulman ${ }^{13}$ argues that in some cases change in practice precedes change in beliefs, while Pajares $^{31}$ suggests that beliefs predict teacher behavior. Since the TAs in the present study were teaching within an inquiry context, we may be able to identify whether this particular practice influences TAs' beliefs about teaching.

\section{PURPOSE}

The purpose of this study was to understand how PD and teaching influence TAs' content knowledge and beliefs within an inquiry-based general chemistry laboratory context. The following research questions informed the study:

1. What changes, if any, in TAs' content knowledge and beliefs about teaching occurred following PD? Were these changes maintained at the end of the semester after follow-up PD and inquiry-based teaching?

2. What differences existed in UTA's and GTA's content knowledge and beliefs about teaching?

3. How, if at all, did TAs' prior experiences impact changes in their content knowledge and beliefs?

Given our understanding of the literature and the engagement of TAs in both inquiry and chemistry concepts, we hypothesized that TAs' content knowledge would increase following PD and that TAs' beliefs would become more aligned with inquiry-based instructional methods. On the basis of the use of degree as a proxy for content knowledge, ${ }^{21}$ we also hypothesized that GTAs would have higher content knowledge than UTAs. Given the research on $\mathrm{K}-12$ teacher belief change and the relationship between beliefs and knowledge, ${ }^{32,33}$ we hypothesized that those TAs with more prior teaching experience would be less likely to change their beliefs. From a theoretical perspective, ${ }^{13,24}$ we also hypothesized that teaching in an inquiry-based laboratory may facilitate changes in TA beliefs.

\section{METHODS}

A multiple-methods approach was employed to explore changes in TAs' content knowledge and beliefs following PD. Specifically, we emphasized quantitative data by utilizing survey scores and coded qualitative belief data from surveys as indicators of change. We then triangulated these data with qualitative interview data to provide a richer explanation than could be provided with just quantitative data alone.

\section{Participants}

Participants for the present study were recruited during the required training for the inquiry-based general chemistry laboratory and included eight female and five male TAs teaching general chemistry laboratory ranging in age from 20 to 26 years old. We included only TAs who consented to 
Table 1. Participant Demographics

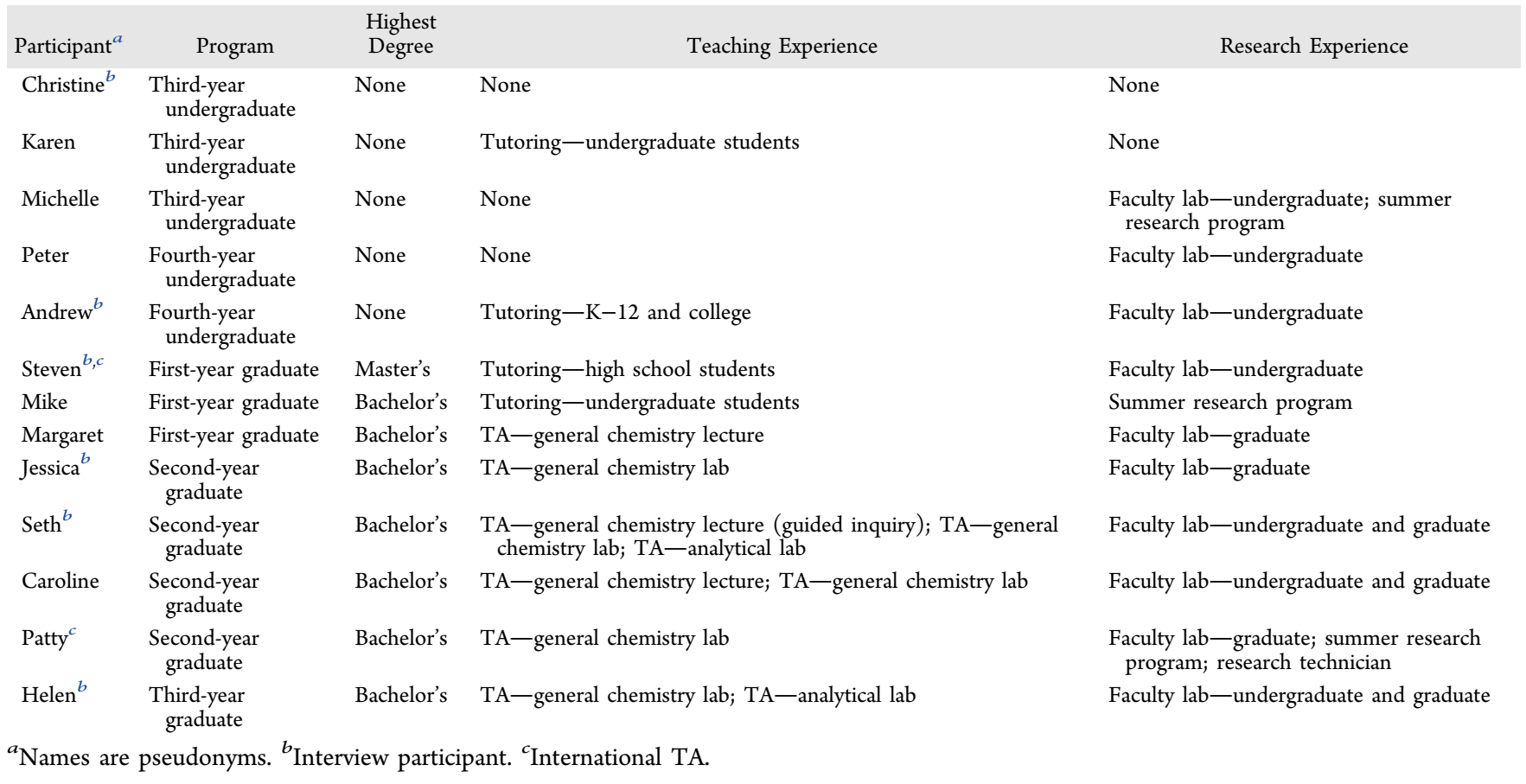

participate and had a complete data set, which represented $43 \%$ of the TAs teaching the course. Of the participants, five reported their ethnicity as Caucasian, five were Asian, one was Middle Eastern, and two declined to provide ethnicity data. In addition, eight were part-time GTAs and five were part-time UTAs. Graduate students taught two sections of lab and were required to teach to maintain their stipends, while undergraduate students taught one section of lab and applied to become a TA. Table 1 provides demographic information including previous teaching and research experience for the 13 TAs. Institutional review board (IRB) consent was obtained for all participants, and pseudonyms are used throughout.

\section{Context}

The TAs taught within a newly implemented guided inquiry general chemistry laboratory course that served approximately 1400 students each semester. In the first semester of general chemistry lab, students had a $3.5 \mathrm{~h}$ lab period that met weekly for 12 weeks. Over the 12 weeks, students worked collaboratively to complete four projects framed as real-world problems. Each week, teams used guiding questions to develop experimental procedures that allowed them to gather data that, when analyzed and interpreted, were used to answer the larger problem. Teams also presented the results of their projects to the class and wrote formal scientific reports at the culmination of each project. Within the guided inquiry laboratory, TAs were responsible for a single section in a room holding two sections taught by two different TAs. The goal was for TAs to interact with students to help facilitate their learning. Specifically, TAs asked guiding questions to help students develop feasible experimental procedures, offered suggestions to students on laboratory techniques when gathering experimental data, encouraged students to critically analyze their work, and provided feedback on students' oral and written work. These expectations were specifically outlined for TAs and embedded within the TA PD outlined below (see Supplemental A for details about TA expectations).
For example, in one guided inquiry project students had three experimental days to identify an unknown white compound using physical and chemical properties of the substance. Prior to the first two experimental days, teams used guiding questions to develop a methodology that employed various techniques (e.g., measuring conductivity, examining solubility) to narrow down the identity of their unknown compound. During the first and second experimentation day, teams gathered and recorded data on the observations from the tests they performed. They interpreted the data to identify their unknown compound. After identifying their unknown compound, teams developed a method to synthesize their compound and ran comparative tests to their unknown compound to confirm its identity. During the final experimental data, teams performed the synthesis reaction and used various separation techniques to isolate their compound to complete the confirmatory tests. Throughout the planning, experimentation, and analysis processes, TAs constantly interacted with students to support the inquiry process. They helped students consider various testing methods and tasked students with developing flowcharts to articulate their process of identification. They troubleshot issues that presented themselves during experimentation and asked questions to facilitate connections between chemical reactions, solubility, and $\mathrm{pH}$. The TAs also facilitated students' consideration of how these data helped them identify their unknown. On the last day of the project, teams presented their results and the TA led a wholeclass discussion on the importance of the work and future studies related to the project.

The PD provided to the TAs was developed from the TA training literature, situated learning theory, and $\mathrm{PD}$ literature as briefly described in the literature review. The PD included a week-long session prior to the beginning of the semester, totaling 25 contact hours and implemented by the first author. During the week, the TAs discussed the course and TA expectations, completed experiments as students, experienced modeling, discussed learning theory, and practiced grading. For 
example, the first author took on the role of the "TA" and interacted with the TAs, who played the role of "students" as they planned, experimented, and presented the results of each project. The modeling allowed the TAs to observe how to facilitate learning, with the hope that modeling would shift TA beliefs to become more aligned with inquiry-based instruction. Throughout the semester the TAs were supported through 14 weekly follow-up PD meetings totaling 30 contact hours. During the weekly follow-up PD meetings, the TAs engaged in group discussions on teaching and grading and led contentbased discussions. For example, TAs would sign up for one of the four projects and lead a whole-class discussion on the content related to that project (see ref 10 and Supplemental B for details about the PD.)

\section{Data Collection}

The participants completed surveys and interviews to assess changes in their content knowledge and teaching beliefs. The use of these multiple data sources allowed for triangulation of data. The survey was administered prior to the PD (pre-PD survey), following the week-long PD (post-PD survey), and at the end of the semester (semester-end survey). The interviews occurred following the week-long PD (interview 1) and at the end of the semester (interview 2). Table 2 overviews the data collection timeline.

\section{Table 2. Data Collection Timeline}

\begin{tabular}{|c|c|c|c|c|}
\hline Data & $\begin{array}{l}\text { Week- } \\
\text { Long } \\
\text { TA PD }\end{array}$ & \multicolumn{3}{|c|}{ Fall 2014 Semester with Follow-Up PD } \\
\hline $\begin{array}{l}\text { Collection } \\
\text { time point }\end{array}$ & $\begin{array}{l}\text { Start of } \\
\text { PD }\end{array}$ & $\begin{array}{l}\text { End of } \\
\text { PD }\end{array}$ & $\begin{array}{l}\text { Within the first month } \\
\text { of follow-up PD and } \\
\text { teaching }\end{array}$ & $\begin{array}{l}\text { End of follow- } \\
\text { up PD and } \\
\text { teaching }\end{array}$ \\
\hline $\begin{array}{l}\text { Data } \\
\text { collected }\end{array}$ & $\begin{array}{l}\text { Pre-PD } \\
\text { survey }\end{array}$ & $\begin{array}{l}\text { Post- } \\
\text { PD } \\
\text { survey }\end{array}$ & Interview 1 & $\begin{array}{l}\text { Semester-end } \\
\text { survey and } \\
\text { Interview } 2\end{array}$ \\
\hline
\end{tabular}

The survey (Supplemental C) included 17 multiple-choice questions, three open-ended content-based questions, and three open-ended questions related to beliefs and TA role. It took approximately $30 \mathrm{~min}$ to complete. The pre-PD survey contained an additional 10 questions about the participants' demographics and prior experience. The content questions were chosen and modified as described in ref 34 to explicitly align with concepts covered in the four guided inquiry projects. For example, in the unknown white compound project, students examine the solubility of their unknown compound, and thus, questions related to chemical reactions and $\mathrm{pH}$ of salts were chosen. A panel of two science educators examined the alignment between the chosen content questions and the concepts covered in the guided inquiry projects and confirmed that these questions were appropriate. A panel of four chemists, including two former TAs, answered the multiple-choice questions, provided explanations for their answers, and provided feedback on the clarity of the questions. The openended survey questions on teaching beliefs were modified from the Teaching Belief Instrument, ${ }^{35}$ which has been previously used with TAs. ${ }^{20}$ A panel of two science education experts reviewed these questions and provided feedback on the clarity of the questions and alignment with the definition of teaching beliefs used in this study.

A subset of six participants were heterogeneously selected on the basis of their UTA/GTA status, international status, and background experience in teaching and research to complete two $30 \mathrm{~min}$ semistructured interviews. The researchers developed the interview questions to further probe each TA's background experiences, assess the TA's perceptions of the PD, and more deeply examine the TA's beliefs about teaching (Supplemental D). The interview questions were reviewed by a panel of two science education experts to support face and content validity. Changes to the survey and interview instruments were made on the basis of the panel members' feedback prior to administration to TAs. All of the interviews were recorded and transcribed.

\section{Data Analysis}

Survey and interview responses were analyzed both quantitatively and qualitatively. Quantitative data on which analyses were performed in SPSS included content questions and coded prior experiences. Participants received a correct score (1) or incorrect score (0) for each multiple-choice content survey item. A rubric was developed for the open-ended content questions and reviewed by a panel of three science education and chemistry content experts to ensure its accuracy and consistency. Each answer to the open-ended questions was scored using the rubric. For example, when asked to give a net ionic equation for a particular reaction, a participant received 3 points for correctly writing the net ionic equation with correct states, 2 points if states were not included or the correct overall chemical equation (not the net ionic equation) was written, 1 point if the net ionic equation was not the correct net ionic equation, and 0 points if the chemical formula for any compound was incorrect.

Mean imputation was used to replace one TA's missing precontent scores. A reliability test was used to identify internal consistency of the presurvey content questions. ${ }^{42}$ Those questions that either had no variability (e.g., all TAs got the question correct) or had a negative correlation with the TAs' overall score (e.g., TA got the question correct but overall did poorly on content) on both the pre- and post-PD surveys were removed before further analysis. The reliability of the remaining questions on the pre-PD survey was high $(n=8$, Cronbach's $\alpha$ $=0.758$ ), providing evidence that these questions measured the TAs' overall content knowledge. Thus, each TA received a percentage correct content score from these questions at all three time points. Because of the small sample size, normality assumptions were tested (e.g., homogeneity of variance, skewedness, and kurtosis). Normality assumptions were violated, so the nonparametric Wilcoxon sign-ranked test was used to identify significant differences between time points for both individual questions and percent correct content scores. Cohen's $d$ effect sizes (ESs) were calculated when significant differences were identified. ${ }^{36}$ Teaching and research experiences were given a hierarchical code, with 0 corresponding to no prior experience and 4 to the most research or teaching experience. Descriptive statistics were used to characterize subgroups of participants (e.g., UTA/GTA, research experience).

Qualitative data related to participants' beliefs about teaching were analyzed using systematic data analysis. ${ }^{43}$ Researcher A and researcher $B$ worked together to develop and refine the codes, code the data, and ensure that the codes represented the data. This use of a second researcher in the data analysis process ensured the trustworthiness of the data used to support the coding schemes. First, a priori categories about teaching beliefs and the role of the TA based on previous TA research were identified and included categories such as "TA as disseminator" versus "TA as facilitator". 5 A participant who 
discussed "facilitator" teaching methods included statements such as TA as a "reference guide" or TA to "facilitate inquiry". Teaching methods categorized as "disseminator" included TA "answering questions" and TA "providing [students] with enough knowledge”.

After initial categories were identified, the corpus of data was read to identify further categories arising from the data. For example, a third teacher belief category, called "TA as facilitator and disseminator", arose inductively out of the data. Participants with a mixture of both disseminator and facilitator responses were categorized using this third category. Survey data were used to identify participants as facilitator (F), facilitator-disseminator (F-D), or disseminator (D) for each time point. For example, participants were coded as $\mathrm{F}$ when all of their responses described facilitation of students and there were no instances of disseminator descriptions. If at least one instance of both facilitator and disseminator responses were found for a particular individual, that participant was coded as $\mathrm{F}-\mathrm{D}$. Once the two researchers agreed that the categories represented the data, researcher B coded a $33 \%$ subset of the interview and survey data. Discrepancies between researcher A coding and researcher $\mathrm{B}$ coding were resolved upon discussion, resulting in $100 \%$ agreement. Researcher A discussed with researcher B any uncertainties from coding the remaining data. Data analysis was complete when the researchers agreed that the qualitative data were accurately represented by the coding scheme and no additional categories arose from the data.

\section{RESULTS}

The purpose of this study was to assess changes in TAs' content knowledge and teaching beliefs within the context of a TA PD, understand differences in UTA/GTA characteristics, and identify relationships between prior knowledge, content knowledge, and teaching beliefs. For each research question, the survey data are presented first, followed by supporting evidence from interviews.

\section{Content Understanding}

A Wilcoxon sign-ranked test indicated that participants' pre-PD content knowledge (mean $(M)=61.90$, standard deviation $(\mathrm{SD})=26.51)$ significantly improved following the week-long $\mathrm{PD}(M=80.22, \mathrm{SD}=11.80)(Z=-2.346, p=0.019$, $\mathrm{ES}=$ $0.651)$. This content knowledge was maintained for participants across the semester after follow-up PD and teaching $(M=$ $75.09, \mathrm{SD}=19.74)(Z=-0.552, p=0.581)$. Analysis of participants' content knowledge by their UTA/GTA status revealed that UTAs entered into the PD with lower content knowledge than their GTA counterparts but scored consistently higher on the content portion of the survey at the end of the week-long PD and at the end of the semester (Table 3).

Table 3. Participant \% Correct Scores on Content-Based Survey Questions

\begin{tabular}{llll} 
& \multicolumn{3}{c}{$M(\mathrm{SD})$} \\
\cline { 2 - 4 } Participant Group & \multicolumn{1}{c}{ Pre-PD } & \multicolumn{1}{c}{ Post-PD } & Semester-End \\
All TAs $(n=13)$ & $61.90(26.51)$ & $80.22(11.80)^{a}$ & $75.09(19.74)$ \\
UTAs $(n=5)$ & $54.28(23.47)$ & $83.81(9.28)$ & $71.43(29.55)$ \\
GTAs $(n=8)$ & $66.67(28.68)$ & $77.97(13.21)$ & $76.19(14.40)$
\end{tabular}

${ }^{a}$ Significant at $p<0.05$. No statistical tests were performed on the subgroups because of the small sample sizes.
Analysis of per-question data revealed that the participants significantly improved their understanding of concepts related to solutions and concentration (Table 4). In particular, the participants significantly improved on calculating the concentration of ions in solution from post-PD to semester-end $(Z=$ $-2.000, p=0.046$, ES $=0.554)$. Following the $\mathrm{PD}$, participants performed significantly better on the open-ended question requiring a calculation of concentration from a percent weight per volume $(Z=-2.226, p=0.026$, ES $=0.617)$. This knowledge was maintained at the end of the semester. These data suggest that the participants' understanding of solutions may have been impacted by the PD experience, as evidenced by the pre- to post-PD change, as well as the teaching experience, as evidenced by the post-PD to semester-end change. The participants' understanding of acid characteristics as assessed by the content question was the least developed and remained as such throughout the study. No changes occurred in the participants' understanding of ionic compounds or in reading the significant digits in a measurement.

\section{TA Beliefs about Teaching}

Overall, the beliefs of the participants shifted to more facilitator-type beliefs as they engaged in PD and taught during the semester (Figure 1). Prior to the PD, all but one participant held either F or F-D beliefs. For example, when asked the best way students learned, Michelle answered "a combination of lecturing, group work, experimentation and then practice problems to see how much they have learned" (pre-PD survey). The combination of dissemination of information (e.g., lecturing) with active-learning strategies (e.g., group work and practice) categorized Michelle as a "facilitator-disseminator". Following PD, all but two participants held facilitator beliefs. For example, Margaret, who initially held disseminator beliefs, indicated the following on her post-PD survey: "My role is to guide the students through the inquiry. I will monitor during lab, provide guiding questions and facilitate discussion." However, some participants discussed their role as "handsoff", describing their role as "an observer, and give them some help when they need" (Steven, post-PD survey) or "Act as a guidance/overseer. Not involved with experimentation or interpretation of results" (Seth, post-PD survey). These data suggest that some TAs completed the PD with the interpretation of a facilitator role as someone who allows students to interact with each other with little or no guidance from the TA.

By the end of the semester, nine TAs held facilitator beliefs, two held facilitator-disseminator beliefs, and one held disseminator beliefs. These beliefs appear to be informed by their experience teaching and not solely by the PD itself. For example, Jessica discussed her role as a guide as follows (interview 2):

My role would be as, kind of a, not mentor, but like a guide...I do not directly teach them something, but if you put a bug in their head and they're like "Wait, what? That is supersaturated?" to me. And then they go back and they can start to figure it out on their own. So I guess in that way, sort of a catalyst to their learning.

Her beliefs aligned with supporting students in their learning rather than telling them answers or not interacting with them at all. She went on to discuss the structure of the course as being one reason why she felt enabled to interact with students in such a way. 
Table 4. Participant Per-Question Content-Based Survey Question Scores

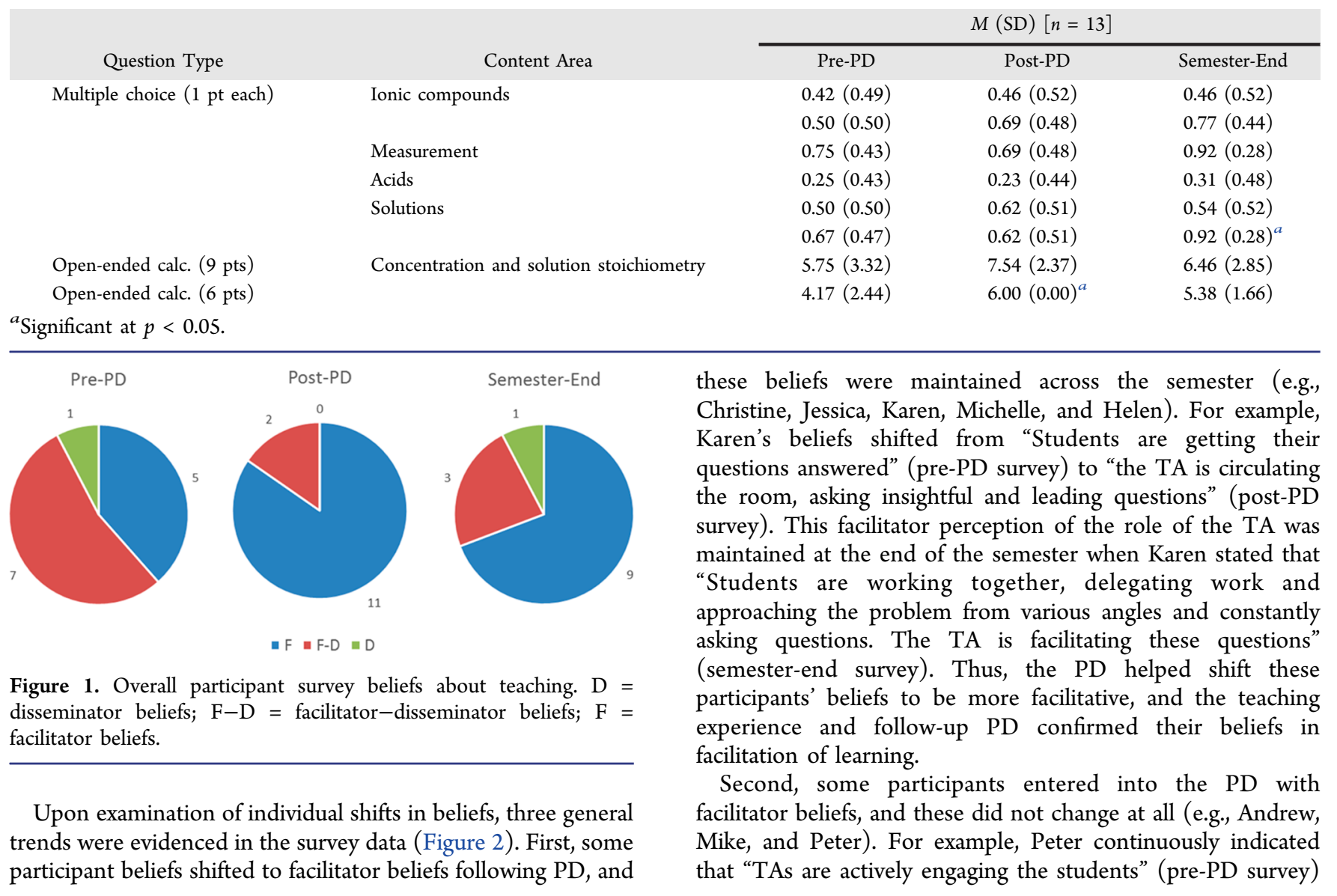

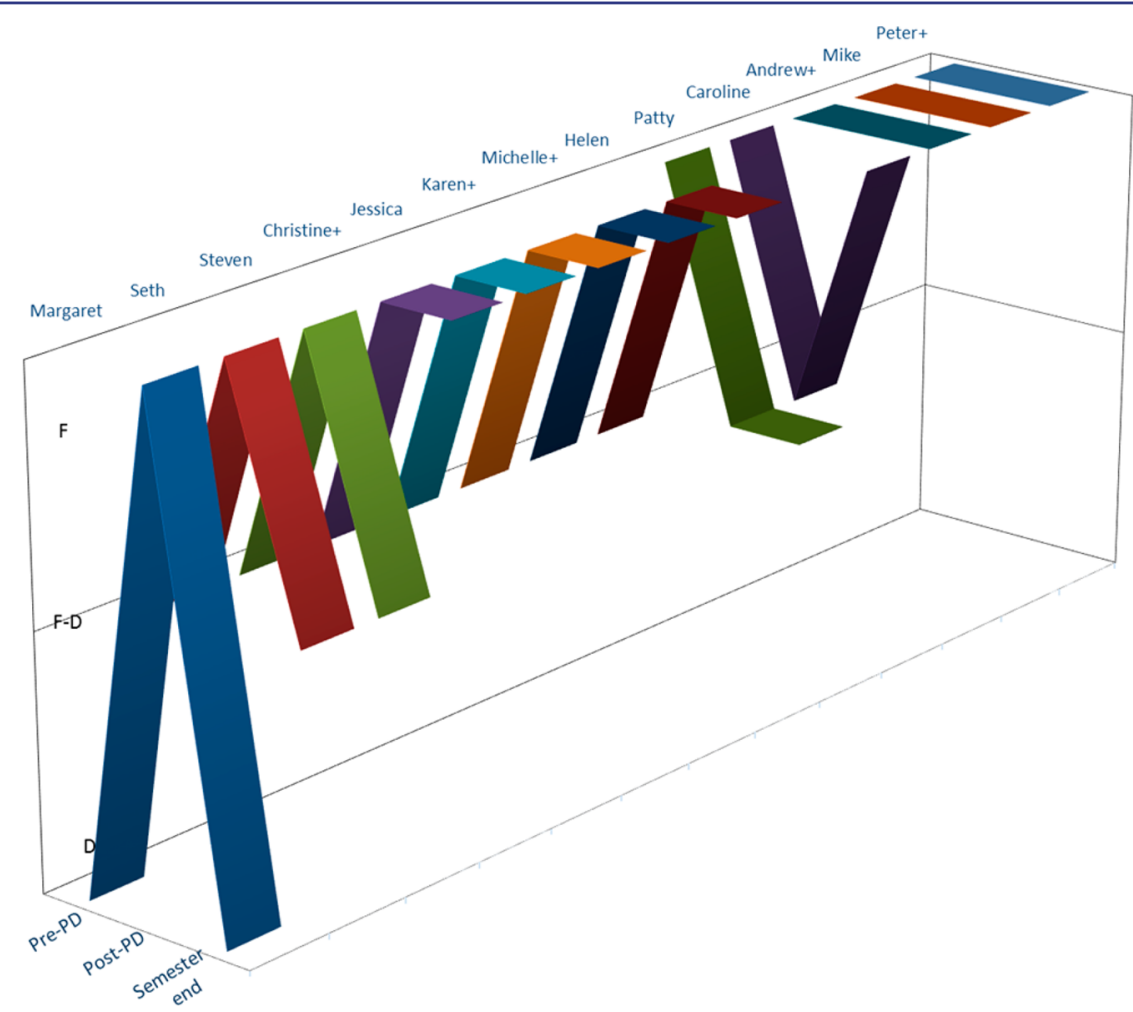

Figure 2. Changes observed in individual participant survey beliefs about teaching. $\mathrm{D}=$ disseminator beliefs; $\mathrm{F}-\mathrm{D}=$ facilitator-disseminator beliefs; $\mathrm{F}=$ facilitator beliefs; + = UTA. While the data are not continuous, the continuous lines across time points are used to illustrate trends among participants. 
Table 5. Participants' Content Knowledge by Prior Experience

\begin{tabular}{lccl} 
& \multicolumn{3}{c}{$M(\mathrm{SD})[n=13]$} \\
\cline { 2 - 4 } \multicolumn{1}{c}{ Prior Experience } & Pre-PD & Post-PD & Semester-End \\
No teaching experience $(n=3)$ & $39.68(9.91)$ & $80.95(9.52)$ & $85.71(4.76)$ \\
Tutoring experience $(n=4)$ & $76.19(19.44)$ & $80.95(20.20)$ & $64.29(30.24)$ \\
TA/teaching experience $(n=6)$ & $63.90(26.51)$ & $79.37(7.17)$ & $76.98(14.57)$ \\
\hline
\end{tabular}

and that the "TA is helping to facilitate the students' learning while not giving the answers" (semester-end survey). These TAs held facilitator beliefs that appeared to be confirmed by both the week-long PD and their teaching experience in an inquiry context.

Third, participants shifted to more facilitator beliefs following PD but reverted during the semester of teaching and follow-up PD (e.g., Margaret, Seth, and Steven). Seth, whose views shifted from facilitator to facilitator-disseminator following a semester of teaching, described his TA experience using an inquiry-based approach as follows: "There are times when you're like, 'I just need to flat out tell you this'. That's just going to be the easiest route for everyone. Most convenient route. No reason to drag on" (interview 2). Seth believed there were instances when providing students with answers rather than facilitating discussions was most appropriate. Seth went on to describe an instance in which he instructed students on a different technique to help them gather more accurate data. Seth's belief that TAs needed to provide students with procedural and lab-technique-related answers was representative of the other participants whose beliefs shifted from facilitator to facilitator-disseminator across the semester.

Differences existed in UTA and GTA beliefs. All five UTAs had facilitator beliefs following the PD, and these beliefs were maintained by the end of the semester. The beliefs of three of the eight GTAs reverted to more disseminator beliefs across the semester. These differences may be explained by the interaction of their prior experiences with their current teaching, as detailed in the following section. UTA and GTA participants also viewed the purpose of lab differently. UTAs typically viewed lab as an application of lecture, while GTAs more frequently believed that lab is a venue for learning through experience. Christine, a UTA, perceived lab to be a venue for applying content and noted that "I think the best way for students to learn is lecture paired with hands-on experience" (semester-end survey). Conversely, Caroline, a GTA, stated that "I think students learn best when they have to struggle with the material first. Students will not learn if the answers are just given to them" (semester-end survey). Caroline believed that lab is a place for students to learn as they grapple with concepts and that passive learning, such as lecture, does not necessarily help students learn. Helen, a third-year GTA, also believed that lab is more than just a place to apply chemistry content. When asked about the inquiry-based approach, she answered, "I feel like I'm helping them learn science as opposed to just doing science...getting them to think about why they're going, what they're doing" (interview 2). Consistent with the majority of the second- and third-year GTAs, Helen's experience helped her to see the laboratory setting as a mode of learning rather than an application of science.

\section{Content, Beliefs, and Prior Experience}

There appeared to be relationships between participants' prior experiences and their content knowledge and teaching beliefs.
Prior Experience and Content Knowledge. The data suggested a relationship existed between participants' prior teaching experience and content knowledge (Table 5). The three participants with no teaching experience had a lower initial content knowledge $(M=39.68 \%)$ than those with tutoring experience $(M=76.09 \%)$ or teaching experience $(M=$ $63.90 \%)$. By the end of the semester, participants with no prior teaching experience increased their content knowledge by $41 \%$, compared with $15 \%$ for those participants with tutoring experience and 5\% for those with TA teaching experience. Thus, it appeared that participants with no prior teaching experience came into the PD with the least content knowledge but made the most gains and ended with the greatest content knowledge.

Christine, whose initial content score was low (47.6\%) and who had no prior teaching experience, talked about her experience in lab. She discussed a situation in which she felt uncomfortable in her own abilities because of her lack of content knowledge (interview 2):

Some of the [students] would come up with some really weird questions, and I was like "I do not even know if that would work". [TA] was awesome to be in the lab with because [TA] is so smart. That is what I probably appreciated most too because I had [TA] there so if I was ever confused I was like, '[TA]', and he was like, really happy to tell me about it. So that was really, really nice. I probably would have felt a lot less comfortable if I did not have [TA].

Christine struggled with students developing their own procedures and "vetting" them as valid ways to approach the problem. She felt that this was due to her own lack of content knowledge; however, the support of a fellow TA with more content knowledge appeared to boost Christine's confidence and ability to engage with students during the planning process.

Prior Experience and Teaching Beliefs. Participants' prior experiences as teachers and students also appeared to interact with their current experiences in teaching and thus inform their beliefs. All five of the second- and third-year graduate participants had previous TA experience in the traditional general chemistry laboratories, and some had inquiry-based teaching experience. These different teaching experiences may have influenced their beliefs about how students learn. Helen described perceived differences in the former traditional curriculum and the new inquiry-based curriculum for the lab course (interview 2):

I felt like last year it was a lot of "make sure your buret is straight up and down. Make sure it is permanent pink". Versus now it is "why would you want to add hydrochloric acid over acetic acid? What are the fundamental differences in those acids?" So getting them to think about why they're doing what they're doing versus what they're doing...It is obviously so fantastic that we're talking about the why behind science.

Her previous teaching experience provided her background from which to appreciate her current inquiry-based teaching, 
and she valued the shift from "what" to "why" and perceived this to be beneficial to students. As shown in Figure 2, Helen's beliefs initially started as facilitator-disseminator but shifted to facilitator. Thus, her prior expository teaching experience may have informed her initial beliefs, but it is possible that her experience in the PD and teaching within the inquiry-based laboratory curriculum may have supported the change in her beliefs.

Seth, a second-year graduate participant with extensive experience teaching through inquiry, held facilitator-disseminator beliefs that shifted to more facilitator but then reverted. When asked about how his role had changed in lab, he answered, "not a whole lot because I already had my POGIL [process-oriented guided inquiry learning] experience, and I liked that system" (interview 2). He went on to explain how he had not changed his approach to interacting with students, despite the change in curriculum, because he had always taken on a more facilitative role. For Seth, the shift to facilitatordisseminator at the end of the semester may have been informed by his prior inquiry teaching within a lecture context and grappling with how to translate that to a laboratory course.

TAs' prior experiences as students may also have influenced their beliefs. Participants with negative learning experiences as students appeared to translate that into their beliefs about the purpose of lab. For example, Andrew talked about his own prior experience in a chemistry course (interview 2):

I hated chemistry because it just seemed stupid...Memorization is involved, solubility rules, and stuff like that. So it is hard when you are amidst all this stuff to really enjoy it. So that is why I was always trying to remind them why things are useful.

Andrew also mentioned that he experienced a guided inquiry approach in chemistry that was ineffective. He noted that during this experience the professor did not facilitate student discussion and learning. Andrew's negative experiences with chemistry appeared to influence his facilitator beliefs about teaching, as he valued the engagement of students in inquiry with an effective instructor. As shown in Figure 2, Andrew's facilitator beliefs were maintained, which may have been due to both his prior experience with ineffective inquiry instruction and his perception of the PD and inquiry-based teaching he engaged as a TA.

\section{DISCUSSION}

The purpose of this investigation was to explore changes in TAs' content knowledge and teaching beliefs within the context of an inquiry-based PD and teaching experience in a general chemistry laboratory course. The results of this investigation suggest that the PD was effective in improving the TAs' overall content knowledge and knowledge about solution chemistry and in shifting the TAs' teaching beliefs to be more facilitative in nature. Further, the TAs' teaching experiences, both current and prior, informed these changes.

A plethora of literature indicates that teacher beliefs, particularly those of experienced teachers, are difficult to change ${ }^{35,37-39}$ even with preservice teacher preparation or PD. The findings of the present study add to the beliefs literature and suggest that the TA PD may have facilitated alignment of TA beliefs with inquiry teaching. In the present study, $62 \%$ of the participants entered PD with more disseminator than facilitator beliefs. However, following the week-long PD, all of these participants' beliefs shifted toward more facilitator-type beliefs. These results contradict those of prior studies; however, the TAs' perceptions of the PD indicate that the TAs appreciated opportunities to complete experiments, have facilitator interactions modeled, and create a community of practice surrounding teaching. ${ }^{10}$ Thus, these opportunities may have been important factors that also helped improve the TAs' content knowledge and modify the TAs' beliefs.

Of the 13 TAs whose beliefs positively changed immediately following the week-long PD (pre- to post-PD), five (63\%) retained these beliefs after follow-up PD and teaching (post-PD to semester-end). We found experiences with inquiry, whether as a teacher or a student, appeared to play a role in the TAs' current teaching beliefs. Some TAs referred to previous experiences as students and in teaching in a traditional laboratory setting as formative in their perspectives on whether inquiry-based teaching could be successful. However, engaging in the PD and actually teaching through inquiry appeared to change these participants' negative perspectives. A number of studies also indicate that prior experience as a student is an important mediator in the development of science teacher's beliefs, $^{32,40,41}$ and our study adds to this literature to suggest that prior experiences with inquiry may inform beliefs about teaching as well.

However, the beliefs of three of the 13 TAs (23\%) reverted to that of disseminator following a semester of teaching and follow-up PD (post-PD to semester-end), which one TA stated was because he just felt he needed to tell students the answer sometimes. One possible explanation for this reversion may be related to the support TAs received during the semester. One component of effective PD not explicitly incorporated into the present study is the use of reflection on teaching. ${ }^{42}$ Providing TAs with multiple opportunities to reflect on their own teaching and consider ways to improve may have helped TAs find alternate methods to deal with situations in which they felt the need to disseminate information. Alternatively, these TAs may not have had a grasp of how knowledge is gained through scientific inquiry, ${ }^{21}$ and thus, their understanding of how to teach in an inquiry-based setting to emulate this process may have been hindered. To our knowledge, no studies have examined TAs' understanding of scientific inquiry and inquiry teaching, so further research in this area is warranted.

To our knowledge, only two studies have examined content knowledge within the PCK framework; ${ }^{15,43,43}$ however, no studies on both UTAs and GTAs in undergraduate science courses have directly examined TA content knowledge. Our data suggest that TAs' content knowledge may impact their comfort in teaching within an inquiry-based laboratory. While there existed significant changes in TAs' content knowledge, the support of peers with greater content knowledge and more teaching experience seemed to be more important in TAs' comfort with their own content knowledge. From a social constructivist perspective, interactions with peers helped TAs make connections between teaching and content knowledge. Examination of declarative, procedural, and conditional content knowledge (CK) alongside PCK and how both peer and student interactions play a role in $\mathrm{CK}$ and PCK is warranted.

\section{IMPLICATIONS AND FUTURE RESEARCH}

While the small sample size and context dependence of our study limit generalizability, we found that the TAs came in with low content knowledge expertise as it related to our laboratory course. Many times GTAs' content knowledge is assumed from their prior degrees ${ }^{14}$ or UTA's content knowledge is assumed from prior enrollment in the course. Our study is the first of its 
kind to measure both UTAs' and GTAs' content knowledge and illustrate that degree as a proxy for content knowledge may not be a valid assumption. We suggest that assessing TAs' content knowledge is essential not only for the instructor but also to allow TAs to identify what they do and do not know.

Very few studies of undergraduate laboratories have examined the use of UTAs in the same manner as GTAs, ${ }^{8,17}$ and our study suggests that UTAs may not come in with the same content knowledge as GTAs but that effective, sustained PD may close this gap. Even more promising is the observation that these UTAs, who had little teaching experience, were receptive to inquiry-based teaching, more so than GTAs with extensive teaching experience. Thus, UTAs may be a viable alternative in staffing the ever-growing large-enrollment introductory laboratory courses.

Our study demonstrates that TAs' teaching practice may influence their beliefs, either positively or negatively. This supports Shulman's argument that teacher practice may precede change in beliefs. With the right PD support, teaching within an inquiry-based setting may lead to a shift in TA teaching beliefs toward facilitator-type beliefs. However, the teaching experience appeared to shift some TAs' beliefs in the opposite direction. Observing TA practice may provide additional insight into how TA-student interactions moderate the relationship between beliefs and practice.

Finally, the culture surrounding TA PD continually presents itself in the literature as an important factor to consider and has been suggested to be more influential on teacher change than the PD itself. ${ }^{44}$ Many times faculty do not value teaching or support for teaching, ${ }^{45}$ which may be a barrier in changing the graduate school culture to place importance on teaching through inquiry-based approaches. A poignant quote indicates one TA's understanding of how faculty members perceive their importance: "TAs are important because they allow the research agenda to move forward." ${ }^{27}$ We have purposefully chosen to describe our TA training as "TA professional development" in the hopes that it can be one small effort to change the way we view how we interact and support our TAs in teaching.

Given the small corpus of studies examining the development of TAs' content knowledge and beliefs in inquiry-based laboratory contexts, ${ }^{10,21,28}$ there is a great need to better understand how best to support TAs so that they have adequate content knowledge and teaching beliefs aligned with inquiry-based instruction. A curriculum is only as good as those who implement it, and examining how TAs implement inquirybased laboratory curricula and how this instruction impacts student learning is a largely unexplored area of research.

\section{ASSOCIATED CONTENT}

\section{Supporting Information}

The Supporting Information is available on the ACS Publications website at DOI: 10.1021/acs.jchemed.6b00373.

Supplemental A (TA expectations document disseminated to TAs during PD) (PDF, DOCX)

Supplemental B (TA PD schedule) (PDF, DOCX)

Supplemental C (TA survey instrument used in the data collection) (PDF, DOCX)

Supplemental D (TA interview instrument used in the data collection) (PDF, DOCX)

\section{AUTHOR INFORMATION}

\section{Corresponding Author}

*E-mail: 1sb4u@virginia.edu.

Notes

The authors declare no competing financial interest.

\section{REFERENCES}

(1) Dotger, S. Exploring and developing graduate teaching assistants' pedagogies via lesson study. Teach. Higher Educ. 2011, 16, 157-169.

(2) Nicklow, J. W.; Marikunte, S. S.; Chevalier, L. R. Balancing pedagogical professional practice skills in the training of graduate teaching assistants. J. Prof. Issues Eng. Educ. Pract. 2007, 133, 89-93.

(3) Kendall, K. D.; Schussler, E. E. Evolving impressions: Undergraduate perceptions of graduate teaching assistants and faculty members over a semester. CBE Life Sci. Educ. 2013, 12, 92-105.

(4) Baumgartner, E. A professional development teaching course for science graduate students. J. Coll. Sci. Teach. 2007, 26, 16-21.

(5) Cho, Y.; Sohoni, S.; French, D. P. Need assessment for graduate teaching assistant training: Identifying important but under-prepared roles. Presented at the Midwest Section Conference of the American Society for Engineering Education, 2010; https://www.asee.org/ documents/sections/midwest/2010/18_Cho.pdf (accessed September 2016).

(6) Poock, J. R.; Burke, K. A.; Greenbowe, T. J.; Hand, B. M. Using the science writing heuristic in the general chemistry laboratory to improve students' academic performance. J. Chem. Educ. 2007, 84, $1371-1379$

(7) Sana, F.; Pachai, M.; Kim, J. A. Training undergraduate teaching assistants in a peer mentor course. Transformative Dialogues 2011, 4 (3), $1-10$.

(8) Chapin, H. C.; Wiggins, B. L.; Martin-Morris, L. E. Undergraduate science learners show comparable outcomes whether taught by undergraduate or graduate teaching assistants. J. Coll. Sci. Teach. 2014, 44 (2), 90-99.

(9) Tien, L. T.; Roth, V.; Kampmeier, J. A. Implementation of a peerled team learning instructional approach in an undergraduate organic chemistry course. J. Res. Sci. Teach. 2002, 39, 606-632.

(10) Wheeler, L. B.; Maeng, J. L.; Whitworth, B. A. Teaching assistants perceptions of a training to support an inquiry-based general chemistry laboratory course. Chem. Educ. Res. Pract. 2015, 16, 824842.

(11) French, D.; Russell, C. Do graduate teaching assistants benefit from teaching inquiry-based laboratories? BioScience 2002, 52, 10361041.

(12) Volkmann, M. J.; Zgagacz, M. Learning to teach physics through inquiry: The lived experience of a graduate teaching assistant. J. Res. Sci. Teach. 2004, 41, 584-602.

(13) Shulman, L. S. Those who understand: Knowledge growth in teaching. Educ. Res. 1986, 15 (2), 4-14.

(14) Sandi-Urena, S.; Cooper, M. M.; Gatlin, T. A. Graduate teaching assistants' epistemological and metacognitive development. Chem. Educ. Res. Pract. 2011, 12, 92-100.

(15) Bond-Robinson, J.; Bernard Rodriques, R. A. Catalyzing graduate teaching assistants' laboratory teaching through design research. J. Chem. Educ. 2006, 83, 313-323.

(16) Diamond, B. S.; Maerten-Rivera, J.; Rohrer, R. E.; Lee, O. Effectiveness of a curricular and professional development intervention at improving elementary teachers' science content knowledge and student achievement outcomes: Year 1 results. J. Res. Sci. Teach. 2014, $51,635-658$.

(17) Seymour, E. Partners in Innovation: Teaching Assistants in College Science Courses; Rowman \& Littlefield: Lanham, MD, 2005.

(18) Norman, G.; Schmidt, H. Effectiveness of Problem-Based Learning Curricula: Theory, Practice and Paper Darts. Med. Educ. 2000, 34, 721-728. 
(19) Harwood, W. S.; Hansen, J.; Lotter, C. Measuring teacher beliefs about inquiry: The development of a blended qualitative/quantitative instrument. J. Sci. Educ. Technol. 2006, 15, 69-79.

(20) Addy, T. M.; Blanchard, M. R. The problem with reform from the bottom up: Instructional practices and teacher beliefs on graduate teaching assistants following a reform-minded university teacher certificate programme. Int. J. Sci. Educ. 2010, 32, 1045-1071.

(21) Sandi-Urena, S.; Gatlin, T. Factors contributing to the development of graduate teaching assistant self-image. J. Chem. Educ. 2013, 90 (10), 1303-1309.

(22) Kurdziel, J. P.; Turner, J. A.; Luft, J. A.; Roehrig, G. H. Graduate teaching assistants and inquiry-based instruction: Implications for graduate teaching assistant training. J. Chem. Educ. 2003, 80, 12061210

(23) Rushton, G. T.; Lotter, C.; Singer, J. Chemistry teachers' emerging expertise in inquiry teaching: The effect of a professional development model on beliefs and practice. J. Sci. Teach. Educ. 2011, $22,23-52$

(24) Hammrich, P. L. Preparing graduate teaching assistants to assist biology faculty. J. Sci. Teach. Educ. 2001, 12, 67-82.

(25) Sandi-Urena, S.; Cooper, M. M.; Gatlin, T. A. Graduate teaching assistants' epistemological and metacognitive development. Chem. Educ. Res. Pract. 2011, 12, 92-100.

(26) Kendall, K. D.; Schussler, E. E. Evolving impressions: Undergraduate perceptions of graduate teaching assistants and faculty members over a semester. CBE Life Sci. Educ. 2013, 12, 92-105.

(27) Luft, J. A.; Kurdziel, J. P.; Roehrig, G. H.; Turner, J. Growing a garden without water: Graduate teaching assistants in introductory science laboratories at a doctoral/research university. J. Res. Sci. Teach. 2004, 41, 211-233.

(28) Burke, K. A.; Hand, B.; Poock, J.; Greenbowe, T. Using the Science Writing Heuristic. J. Coll. Sci. Teach. 2005, 35 (1), 36-41.

(29) Gardner, G. E.; Jones, M. G. Pedagogical preparation of the science graduate teaching assistant: Challenges and implications. Sci. Educ. 2011, 20 (2), 31-41.

(30) Mansour, N. Science Teachers' Beliefs and Practices: Issues, Implications and Research Agenda. Int. J. Environ. Sci. Educ. 2009, 4 (1), 25-48.

(31) Pajares, M. F. Teachers' beliefs and education research: Cleaning up a messy construct. Rev. Educ. Res. 1992, 62, 307-332.

(32) Eick, C. J.; Reed, C.J. What makes an inquiry-oriented science teacher? The influence of learning histories on student teacher role identity and practice. Sci. Educ. 2002, 86, 401-416.

(33) Luft, J. A. Changing inquiry practices and beliefs: The impact of an inquiry-based professional development programme on beginning and experienced secondary science teachers. Int. J. Sci. Educ. 2001, 23, $517-534$.

(34) Kautz, J.; Kennedy, R.; Kreutz, B.; Hermann, C.; Pienta, N. Principles of Chemistry: A Molecular Approach Instructor Resource Center on CD/DVD Test Bank Questions; Pearson Prentice Hall: Upper Saddle River, NJ, 2010.

(35) Luft, J. A.; Roehrig, G. H. Capturing science teachers' epistemological beliefs: The development of the teacher beliefs interview. Electron. J. Sci. Educ. 2007, 11 (2), 38-63.

(36) Corder, G. W.; Foreman, D. I. Nonparametric Statistics for NonStatisticians; Wiley \& Sons: Hoboken, NJ, 2009; pp 39-56.

(37) Cronin-Jones, L. L. Science teacher beliefs and their influence on curriculum implementation: Two case studies. J. Res. Sci. Teach. 1991, 28, 235-250.

(38) Pajares, F. Self-efficacy beliefs in academic settings. Rev. Educ. Res. 1996, 66, 543-578.

(39) Yerrick, R.; Parke, H.; Nugent, J. Struggling to promote deeply rooted change: The "filtering effect" of teachers' beliefs on understanding transformational views of teaching science. Sci. Educ. 1997, 81, 137-159.

(40) Laplante, B. Teachers' beliefs and instructional strategies in science: Pushing analysis further. Sci. Educ. 1997, 81, 277-294.
(41) Southerland, S. A.; Gess-Newsome, J. Preservice teachers' views of inclusive science teaching as shaped by images of teaching, learning and knowledge. Sci. Educ. 1999, 83, 131-150.

(42) Ebert-May, D.; Derting, T. L.; Henkel, T. P.; Maher, J. M.; Momsen, J. L.; Arnold, B.; Passmore, H. A. Breaking the Cycle: Future Faculty Begin Teaching with Learner-Centered Strategies after Professional Development. CBE Life Sci. Educ. 2015, 14, ar22.

(43) Hale, L. V. A.; Lutter, J. C.; Shultz, G. V. The development of a tool for measuring graduate students' topic specific pedagogical content knowledge of thin layer chromatography. Chem. Educ. Res. Pract. 2016, 17, 700-710.

(44) Luft, J. A.; Hewson, P. W. Research on teacher professional development programs in science. In Handbook of Research on Science Education; Abell, S. K., Lederman, N. G., Eds.; Routledge: New York, 2014; pp 899-910.

(45) Shannon, D. M.; Twale, D. J.; Moore, M. S. TA teaching effectiveness. J. Higher Educ. 1998, 69, 440-466. 